training, and one-quarter had no meaningful work. Shunts had been changed 103 times in 29 patients still alive. Encouragement and support for the families seemed essential in improving social development of patients in adolescence.

\title{
PSEUDOTUMOR CEREBRI WITHOUT EDEMA
}

The pathologic findings in two adult patients with idiopathic intracranial hypertension (IIH) who died unexpectedly are reported from the University of Iowa College of Medicine, Iowa City. Patient 1 died of cardiac arrest during operation for duodenal ulcer, and patient 2 died in her sleep of unknown cause. No histologic evidence of either intracellular or interstitial brain edema was found at autopsy. Arachnoid granulations were not available for study. (Wall $M$ et al. Idiopathic intracranial hypertension. Lack of histologic evidence for cerebral edema. Arch Neurol Feb 1995;52:141-145). (Reprints: Dr Wall, Department of Neurology, University of Iowa, College of Medicine, 200 Hawkins Dr, Iowa City, IA 52242).

COMMENT. The absence of cerebral edema was in agreement with the report of 3 patients studied by Greer and in contrast to a finding of interstitial and intracellular edema in cortical biopsies of 10 patients reported by Sahs and Joynt. A review of tissue from 3 of the Sahs and Joynt cases, one a girl aged 17 years, showed artifactual changes and no convincing evidence of edema on re-examination of slides. The authors recommend measures of brain water content of frozen tissue and examination of arachnoid granulations when available, in future investigations of pathogenesis of pseudotumor cerebri.

The MRI has been used to clarify the pathophysiology of pseudotumor in 7 children, aged 6 months to 13 years. Normal signal intensity in the white matter was in keeping with absence of brain edema, as reported in the Iowa autopsy specimens. (Connolly MB et al. 1992; see Progress in Pediatric Neurology II, 1994, pp 336-7).

\section{HEAD TRAUMA}

\section{MANAGEMENT OF CONCUSSION IN YOUNG ATHLETES}

The discharge instructions received by youth athletes hospitalized for a sports-related closed head injury over a 5-year period (1987-1991) were examined at the Children's Hospital and University of Alabama, Birmingham, AL. Injury severity was graded according to Cantu's 1986 guidelines and compared to the Colorado Medical Society guidelines as endorsed by the American Academy of Pediatrics. Concussions were grade 1 (least severe) in 8 patients (24\%), grade 2 in $10(30 \%)$, and grade 3 (most severe) in $15(45 \%)$. Discharge instructions were inappropriate and not in compliance with guidelines in 8 of 10 patients with grade 2 , and in all of 15 with grade 3 concussions. The majority had uneventful hospital courses, but most received inadequate counseling regarding potential future risk. Of 23 for whom instructions were inadequate, 3 were allowed to return to sports participation too quickly, and no instructions were documented for 20 (87\%) patients. (Genuardi FJ, King WD. Inappropriate discharge instructions for youth athletes hospitalized for concussion. Pediatrics February 1995;95:216-218). (Reprints: Dr FJ Genuardi, University of Florida Health Science Center, Dept of Pediatrics, 653-1 W 8th St, Jacksonville, FL 32209). 